\title{
Vickers and Knoop Indentation Microhardness Study of $\beta$-SiAlON Ceramic
}

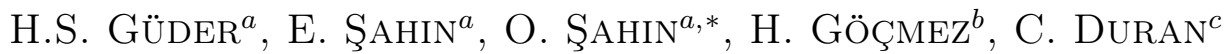 \\ And H. Ali ÇETINKARA ${ }^{a}$ \\ ${ }^{a}$ Department of Physics, Micro/Nanomechanic Characterization Laboratory \\ Mustafa Kemal University, Hatay, Turkey \\ ${ }^{b}$ Department of Ceramic Engineering, Dumlupinar University, Kutahya, Turkey \\ ${ }^{c}$ Materials Science and Engineering Department, Gebze Institute of Technology, Kocaeli, Turkey
}

(Received December 13, 2010; in final form October 28, 2011)

\begin{abstract}
In this paper, analysis and interpretation of mechanical property measurements of $\beta$-SiAlON ceramic were reported. Indentation microhardness of $\beta$-SiAlON ceramic was measured using the Knoop and Vickers indenters. The analysis of the Vickers indentation microhardness data reveals the reverse indentation size effect that is the apparent microhardness increases with increasing applied indentation test load. However, the Knoop indentation microhardness data exhibit indentation size effect that is the apparent microhardness increases with decreasing applied test load. The experimental Knoop microhardness data was analyzed using Meyer's law, elastic-plastic deformation model, proportional specimen resistance model, and Hays-Kendall's model. As a result, modified proportional specimen resistance model is found to be the most effective one for the load-independent $\left(H_{\mathrm{LI}}\right)$ microhardness determination of the SiAlON ceramic. It was seen that different models used to analyze the data obtained from the Vickers indentation do not give the same intrinsic hardness value. We also present the calculation of the Young modulus, $E$, of the $\beta$-SiAlON ceramic.
\end{abstract}

PACS: 62.20.-x, 62.20.Qp, 62.20.de

\section{Introduction}

Hardness of a material is defined as its resistance to plastic deformation usually when the indentation test is carried out. The principles of indentation consist of applying a given test load and, subsequently, measuring the dimensions of the residual impression left in the material once the indenter has been withdrawn. Hardness of the material is then defined as the ratio between the indentation load and a parameter representing the area of the residual impression which depends on the shape of the indenter and the method employed for the hardness calculation. Hardness of a brittle material as determined by conventional tests (Vickers, Knoop, Berkovich, Rockwell, etc.) is a measure of the material's resistance to deformation, densification displacement and fracture [1]. Hardness measurements are frequently undertaken but poorly performed on ceramics materials and often misunderstood because of the relationship between the measured material's response and the microstructure features. Thus, in actual work it was seen that hardness

\footnotetext{
* corresponding author; e-mail: osahin@mku.edu.tr
}

shows a dependence on the test load on the material. The load dependence is found to vary with type of materials and experiments types. Typically, four types of results have been reported so far. These are shown in Fig. 1.

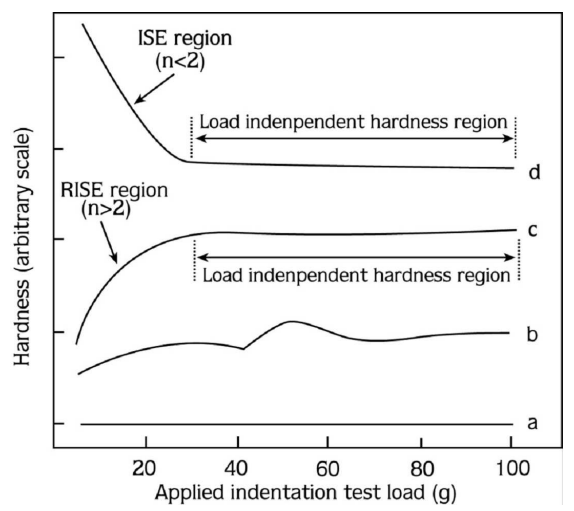

Fig. 1. Schematic representation of hardness applied indentation test load variation.

In $a$ type variation, hardness is constant with respect to load. Such behaviour presumes an ideal instrument response and an ideal material response. This load- 
-independent behaviour has been observed by several researchers $[2,3]$. In $b$ type variation, the load-hardness curve consists of kinks, maxima and minima. Such behaviour has been observed in some organic crystals [4] and some polymeric materials [5]. In $c$ type variation, hardness increases with increasing load. Load variation of this type has been observed in several studies [6-8]. This behaviour is called reverse indentation size effect (RISE). In $d$ type variation, hardness decreases with increasing load. Hardness shows a step decrease with an increasing critical load and thereafter reaches saturation. This behavior is called indentation size effect (ISE) [9-11].

$\beta$-SiAlONs, which are ceramic alloys of silicon nitride and aluminum oxide, were developed as an economically and functionally superior alternative to hot-pressed silicon nitride (HPSN). Economically driven research looks for simplification of technology, elimination of gas-pressure sintering and lowering of densification temperature. That aim can be achieved by application of nanopowders [12] or recently proposed mechanochemical processing [13]. The latter changes significantly development of the microstructure in comparison to the standard $\beta$-SiAlON ceramic manufactured by gas pressure sintering and the relevant mechanical properties. Nevertheless, the new $\beta$-SiAlON ceramics are of interest for the new fields of application and the microstructure related properties should be determined in the new class of $\beta$-SiAlON ceramic.

In this study, therefore, the mechanical properties of porous SiAlON-based ceramic, which is prepared by pressureless sintering of mechanically activated $\beta$-SiAlON precursor powders, have been characterized by using the Vickers and Knoop indenter.

\section{Theoretical background}

Indentation microhardness measurements of $\beta$-SiAlON ceramic were performed with a Future-Tech FM 700 microindentation hardness tester at the room temperature. The Vickers and Knoop indenters were used with loads ranging from 0.245 to $9.8 \mathrm{~N}$. Loads were applied for $15 \mathrm{~s}$ to measure diagonals of the indentations. The indentation diagonal lengths were measured with Nikon MA 100 inverted metal microscope using the Clemex professional microscopy image analysis software. $50 \times$ and $20 \times$ objective lenses were used on the Nikon MA 100 instrument in the present study. For a particular load, at least ten well-defined impressions were considered.

For the Vickers hardness test, the indenter is a square-based pyramid for which the angle between the two opposite sides is equal to $136^{\circ}$ (Fig. 2a). The representative area corresponds to the true area of the contact between the pyramid and the material at the maximum load of the indentation. By means of simple geometrical considerations, the contact area may be expressed as a function of the diagonal of the indent. The Vickers microhardness $\left(H_{\mathrm{V}}\right)$ is calculated using the following formula:

$$
H_{\mathrm{V}}=\frac{P}{A_{\mathrm{V}}}=\frac{P}{\left(\frac{d^{2}}{2}\right) \sin \left(\frac{\psi}{2}\right)}=1.8544 \frac{P}{d^{2}},
$$

where $P$ is the applied test load in N, $d$ is the average of two indentation diagonal lengths in $\mu \mathrm{m}$, and 1.8544 is a geometrical constant of the diamond pyramid.

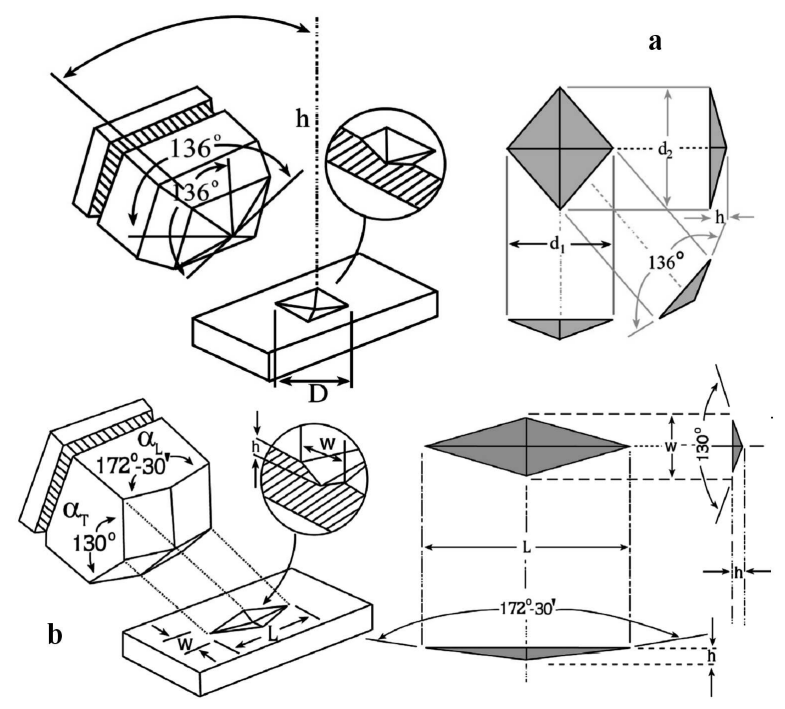

Fig. 2. (a) Vickers indentation and indentation diagonal length, (b) Knoop indentation and indentation diagonal length.

The Knoop microhardness test used a lozenge-based pyramid with the angle $\theta$ between the two opposite faces being $172^{\circ} 30^{\prime}$ and the angle $\phi$ between the other two faces being $130^{\circ}$ (Fig. 2b). Calculation of the Knoop microhardness number considers the projected area of the contact in the plane of the material. The projected area is calculated using the length of the indent by knowing the theoretical relationship between the length and the width of the impression. The Knoop microhardness $\left(H_{\mathrm{K}}\right)$ is generally calculated using the following formula:

$$
H_{\mathrm{K}}=\frac{P}{A_{\mathrm{K}}}=\frac{P}{L^{2} \frac{\tan \left(\frac{\phi}{2}\right)}{2 \tan \left(\frac{\theta}{2}\right)}}=14229 \frac{P}{L^{2}},
$$

where $P$ is the applied test load in N, $L$ is the long indentation diagonal lengths in $\mu \mathrm{m}$, and 14.229 is the geometrical constant of the diamond pyramid.

\section{Experimental procedure}

The initial batch consisted of $89.3 \mathrm{wt} \%$ of $\alpha-\mathrm{Si}_{3} \mathrm{~N}_{4}$ (H.C.Starck-B7, $10-15 \mathrm{wt} \%$ of $\beta-\mathrm{Si}_{3} \mathrm{~N}_{4}$ ), $5.7 \mathrm{wt} \%$ of AlN (H.C.Starck-C) and 5 wt $\%$ of $\mathrm{Y}_{2} \mathrm{O}_{3}$ (H.C.Starck-grade $\mathrm{C}$ ). The mechanochemical processing of the batch was performed in the MPP-1 planetary mill (TTD, Russia) with the ball-to-powder ratio $6: 1$ for 30 min with the acceleration of the centrifugal field of $28 \mathrm{~g}$ ( $\mathrm{g}$ is the gravitational acceleration). The resultant powder showed high specific surface area by BET $\left(18.7 \mathrm{~m}^{2} / \mathrm{g}\right.$, ASAP 2010), significant crystal lattice damage as confirmed by X-ray 
diffraction (XRD) (X'PERT) and increased oxygen content (3.9 wt\%, ELTRA ON). The Si:Al ratio as well as the measured content of oxygen were sufficient to produce $\beta$ -SiAlON ceramic with $z$ value of 0.4 . The mechanochemically processed powder was uniaxially pressed into the form of tablets with $20 \mathrm{~mm}$ in diameter and $5-6 \mathrm{~mm}$ in height. The pressed tablets were contained within a powder bed of $\mathrm{Si}_{3} \mathrm{~N}_{4} / \mathrm{BN}$ in a BN crucible with a lid. Densification was carried out in a graphite furnace (Thermal Technology), in which nitrogen flow was kept at $1600^{\circ} \mathrm{C}$ for $2 \mathrm{~h}$. Further details of the material preparation are given in Ref. [14].

Density of the resultant ceramic was determined by the Archimedes technique in distilled water. XRD studies were performed on the polished cross-section of the tablets. The $\alpha / \beta$ ratio was determined from the X-ray intensities of planes 102 and 210 for $\alpha$-phase, 101 and 210 for $\beta$-phase [15]. The $z$-value of $\beta$-SiAlON was determined from the unit cell parameters according to the Ekström et al. formula [16]. Microstructural characterization was performed by scanning electron microscopy (Hitachi) equipped with an energy-dispersive X-ray spectometer (EDS).

\section{Results and discussion}

\subsection{Characterization of the resultant SiAlON}

The resultant ceramic specimens were characterized by high $\alpha \rightarrow \beta$ transition $(\alpha / \beta=0.12)$ with the $z$ value close to 0.3 , slightly lower than the desired value of 0.4. Density of the specimens was $3.07 \pm 0.01 \mathrm{~g} \mathrm{~cm}^{-3}$. If the density of the initial powder (3.15) is taken as the final value of a dense material, then we could assume that the relative density was 0.97 . Bending strength was $340 \pm 29 \mathrm{MPa}$ and low standard deviation shows good repeteability of the measurement. Measurement of ultrasonic wave velocity showed high anisotropy in the parallel and perpendicular direction $\left(A_{\mathrm{V}}=6 \%, A_{\mathrm{E}}=8.1 \%\right)$ indicating elongation of the grains along the diameter of the specimen as the tablets were uniaxially pressed. Moreover, it has been found out that the ultrasonic wave was significantly suppressed during the propagation in the material if high frequency was applied $(12 \mathrm{MHz})$.

\subsection{Vickers microindentation data analysis}

Figure 3 shows the variation of $H_{\mathrm{V}}$ as a function of applied indentation test loads ranging from 0.245 to $9.8 \mathrm{~N}$ for the specimen. The variation of $H_{\mathrm{V}}$ with applied indentation test load shows that the $H_{\mathrm{V}}$ increases with increasing applied indentation test load, which can be considered as the reflection of the reverse indentation size effect [6-8]. Similar behaviour was observed in $S$-phase SiAlON ceramic under high load [17], TiCN cermets [7], glasses [18], and single crystals [19]. In contrast to normal ISE, under the effect of RISE, material undergoes a relaxation, which involves a release of the indentation stress along the surface away from the indentation site, which may be because of the crack formation, dislocation activity, and/or elastic deformation of the tip of the indenter. For brittle materials, it is common observation that cracking occurs during indenter loading half-cycle. Feltham and Banerjee [20] first suggested that RISE might be released to the energy loss owing to the cracking of the specimens during indentation. Owing to such cracking, a fraction of energy is spent in crack propagation and a small indentation size results. Thus, the indentation tests yield an apparently high hardness value. Keeping this in view, it is reasonable to argue that at low load, the dislocation plasticity can lead to more deformation and therefore, leads to reduce hardness in $\beta$-SiAlON sample. In addition, it can be noted that the indentation response at last two indentations involves cracking (Fig. 3b).

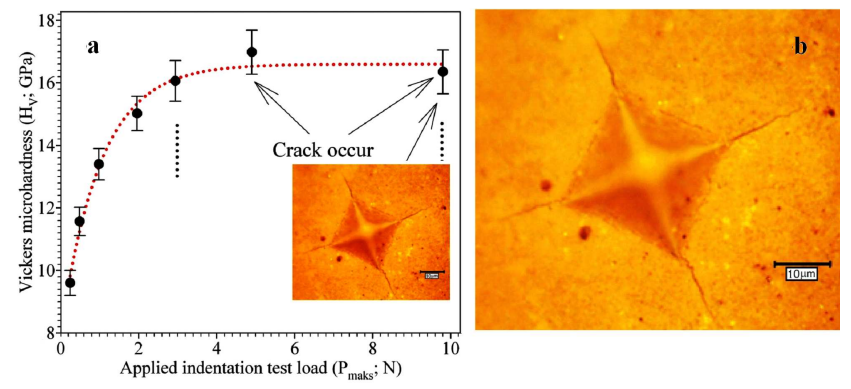

Fig. 3. (a) Variation of the Vickers microhardness with the applied indentation test load, (b) Vickers indentation image of $\beta$-SiAlON.

Indentation techniques could also be used for measuring fracture toughness. When a sharp tip such as Vickers, Berkovich or a cube corner diamond is indented into bulk brittle materials, radial cracking usually occurs after a critical load has been reached, which allows ones to calculate fracture toughness based on the maximum indentation load and the crack length [21,22]. The value of hardness was used to calculate the fracture tougness $\left(K_{\mathrm{IC}}\right)$ through the Antis and Evans methods according to following:

$$
\begin{aligned}
K_{\mathrm{IC}} & =0.16 H_{\mathrm{V}} a^{\frac{1}{2}}\left(\frac{c}{a}\right)^{-3 / 2} \text { (Evans), } \\
K_{\mathrm{IC}} & =\alpha\left(\frac{E}{H}\right)^{1 / 2}\left(\frac{P}{c^{3 / 2}}\right) \text { (Antis) },
\end{aligned}
$$

where $c$ is the crack length (from one crack tip to another), $a$ is the half of indent length $(\mu \mathrm{m})$ and $H_{\mathrm{V}}$ is the Vickers microhardness $(\mathrm{GPa})$. According to the Evans model the $K_{\mathrm{IC}}$ is $2.2 \pm 0.15 \mathrm{MPa} \mathrm{mm}{ }^{1 / 2}$.

\subsection{Application of different models for the $\beta$-SiAlON ceramic}

Meyer's law correlates the indentation size, $d$, to the indentation load, $P$, in the following manner:

$$
P=A d^{n},
$$

where the exponent, $n$, Meyer index, is a measure of 
ISE and $A$ is constant. These values can be found from $\ln P$ vs. $\ln d$ graph. For normal ISE behaviour, the exponent $n<2$. When $n>2$, there is reverse ISE behaviour. According to the definition of the apparent hardness (Eq. (3)), no ISE would be observed for $n=2$. In this study, $n$ value is 2.355. Calculated $n$ values point out an increase of the Vickers indentation hardness with increasing applied indentation test load that are in agreement with a RISE (Fig. 3) and with other reported results $[6,7]$.

The experimental data on dependence of $H_{\mathrm{V}}$ on applied indentation test load can be explained by the HaysKendall approach [23]. They proposed that there exists a minimum applied test load $W$ (test specimen resistance) necessary to initiate plastic deformation, below which only elastic deformation occurs

$$
P=W+C_{1} d^{2},
$$

where $W$ is the minimum load to initiate plastic deformation and $C_{1}$ is a load-independent constant. From Eq. (4), a plot of $P$ versus $h^{2}$ would yield a straight line, where the parameters of $W$ and $C_{1}$ can easily be calculated from the intersection point and the slope of the curve, respectively. It was found that the $\beta$-SiAlON ceramic, showing reverse ISE plot of $P$ versus $h^{2}$, give relatively poor fits and negative value of $W$ for the data.

Conventional indentation hardness tests involve the measured size of a residual plastic impression in the specimen as a function of the indenter load. The elastic recovery would occur in the vicinity of the remaining indentation impression after the indenter is removed, so that the indentation size would be shortened to a certain degree. According to the elastic plastic deformation (EPD) model the load dependence of indentation size for the normal ISE is given by

$$
P=C_{2}\left(d+d_{0}\right)^{2},
$$

where $C_{2}$ is a load-independent constant and $d_{0}$ is the correction term in $d$ due to indenter tip bluntness and elastic recovery [6]. The values of $C_{2}$ and $d_{0}$ were calculated from the plots of $P^{1 / 2}$ versus $d$. It was found that the $\beta$-SiAlON ceramic, showing reverse ISE, the correction term is a negative quantity.

Recently, Li and Bradt [24] have tried to explain the ISE with the aid of their "proportional specimen resistance" (PSR) model. According to the PSR model, the indentation test load $P$ is related to the indentation diagonal length $d$ as follows:

$$
P_{\max }=a_{1} d+a_{2} d^{2}=a_{1} d+\left(\frac{P_{\mathrm{c}}}{d_{\mathrm{c}}^{2}}\right) d^{2},
$$

where the first coefficient $\left(a_{1}\right)$ is responsible for the dependence of hardness on load and the second coefficient $\left(a_{2}\right)$ contributes to the load-independent behavior. $P_{\mathrm{c}}$ is the critical applied load, above which the microindentation hardness becomes load-independent and $d_{\mathrm{c}}$ is the corresponding indentation diagonal length. Now Eq. (6) can be rearranged as

$$
\left(\frac{P_{\max }}{d}\right)=a_{1}+a_{2} d \text {. }
$$

According to Eq. (7), a plot of $P_{\max } / d$ vs. $d$ must yield a straight line and the $a_{1}$ and $a_{2}$ parameters can easily be determined from the intersection point and the slope of the curve, respectively. The $a_{1}$ is negative quantity as that of $d_{0}$.

From the results of the analysis presented above, it may be noted that, as expected for the reverse ISE, the values of all the correction factors $W, d_{0}$ and $a_{1}$ in the Hays-Kendall, EPD and PSR-type approaches, respectively, are negative for the experimental $P$ versus $d$ data. This means that in the case of the reverse ISE a specimen does not offer resistance or undergo elastic recovery, as postulated in the Hays-Kendall approach and PSR-type and EPD models, but undergoes relaxation involving a release of the indentation stress away from the indentation site. This leads to a larger indentation size and hence to a lower hardness at low loads. As indicated by the negative values of loads $W$ for the crystals, the concept of Hays-Kendall, which states that there is a minimum load below which only elastic deformation takes place, can be rejected [6].

In an attempt to address the reverse ISE, recently $\mathrm{Li}$ and Bradt [24] considered that at the point of maximum penetration during the loading half-cycle, the applied indentation test load is balanced by the total specimen resistance, which is composed of four components due to: (i) friction at the indenter/specimen facet interface (frictional component), (ii) elastic deformation, (iii) plastic deformation, and (iv) specimen cracking. According to these authors, frictional and elastic effects lead to the normal ISE while indentation cracking contributes to the reverse ISE. In the case of indentation cracking, the apparent hardness measured by a Vickers diamond indenter can be analytically assessed [25]:

$$
H_{\text {app }}=\lambda_{1} K_{1}\left(\frac{P}{d^{2}}\right)+K_{2}\left(\frac{P^{5 / 3}}{d^{3}}\right),
$$

where $d$ is the indentation diameter, and $\lambda_{1}, K_{1}$ and $K_{2}$ are constants. The constant $K_{2}$ depends on the applied load $P$ while $K_{1}$ is a geometrical conversion factor whose value depends on the indenter geometry. For a perfectly brittle solid,

$$
\lambda_{1}=0 \text { and } H_{\mathrm{app}}=K_{2}\left(\frac{P^{5 / 3}}{d^{3}}\right) .
$$

After analyzing a large number of experimentally measured hardness data, Sangwall [6] proposed a modified relationship

$$
H_{\mathrm{V}}=K\left(\frac{P^{\frac{5}{3}}}{d^{3}}\right)^{m},
$$

where $K$ and $m$ are constants and the value of $m$ is reported to be around $0.5-0.55[6]$.

Although the deformation dominated the hardness response at lower load, the observation of indent-induced radial cracking has been made at intermediate and higher loads. In order to critically analyze our experimental 
data, the measured apparent hardness values are plotted against $\left(P^{5 / 3} / d^{3}\right)$ on $\log$ scale, in Fig. 4 . It is clear from Fig. 4 that the measured data can be fitted closely with the linear correlation. The value of $m$, in the present case, was recorded to be 0.396 , which is a bit lower than the earlier report [7].

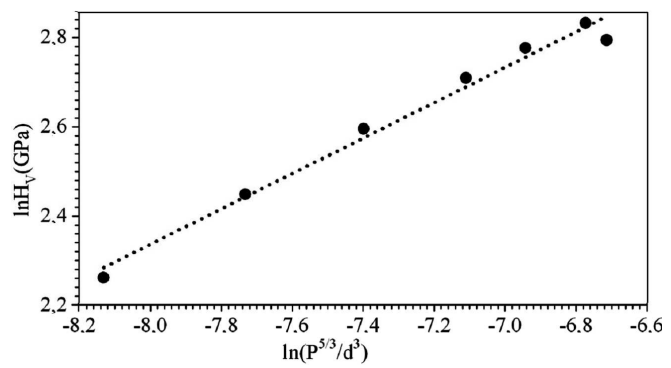

Fig. 4. Plot of $\ln H_{\mathrm{V}}$ versus $\ln \left(P^{5 / 3} / d^{3}\right)$.

From the analysis above, it is clear that the variation of the apparent hardness with load can be attributed to the change of the cracking behavior of the materials, which is ultimately controlled by the resultant microstructures evolving during densification. It is obvious that the microstructural features are such that the cracking behavior is different at lower and higher load. At lower loads, the plastic deformation is predominant; as a result, much of the indentation energy is consumed for material flow and displacement, which lowers the apparent hardness. Whereas, at higher loads, the cracking (Fig. 3b) is more predominant compared to the plastic deformation; consequently, relatively more energy is consumed for the crack initiation and the propagation.

From Fig. 4, it is obvious that Eq. (10) based on the indentation induced cracking (IIC) model does not distinguish normal and reverse ISE. According to the IIC model, this behaviour is expected only for purely brittle materials. However, in the Sangwall [6] analysis both brittle and relatively plastic materials have been included. Therefore, it may be concluded that the IIC model is not satisfactory for the explanation of the reverse ISE.

\subsection{Knoop microindentation data analysis}

The applied indentation test load dependence of the Knoop microhardness data obtained from the examined material is shown in Fig. 5. Microhardness values decrease with increasing peak indentation test load. Apparent $H_{\mathrm{K}}$ is a function of applied low indentation test loads, where there is no constant value for the hardness ( $H_{\mathrm{LD}}$; load-dependent hardness). At high indentation test loads, hardness is constant with respect to indentation test load and a single, well-defined hardness value exists $\left(H_{\mathrm{LI}}\right.$; load-independent hardness). $H_{\mathrm{LI}}$ has also been referred to "true" hardness in some literature. This behavior is called ISE $[6,9,19]$.

In order to describe ISE behaviour of different materials, several models for the relation between the applied

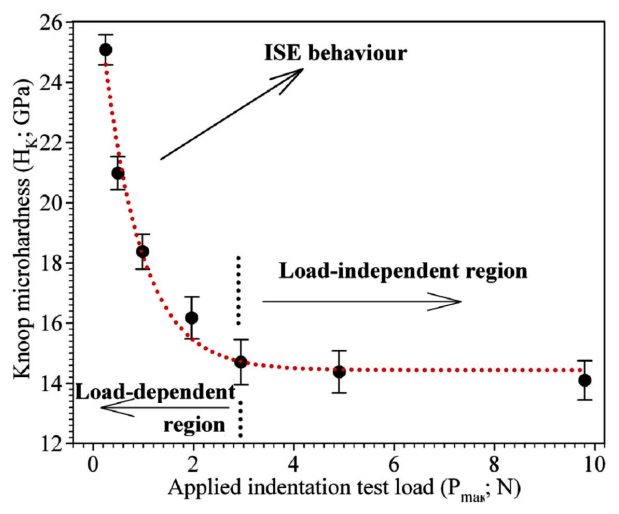

Fig. 5. Variation of the Knoop microhardness with the applied indentation test load.

indentation test load and the indentation diagonal length have been reported in the literature $[7,9]$. The most common explanation for ISE found in the literature is directly related to intrinsic structural factors of test material. As demonstrated in the literature, one needs to fit the experimental data according to Meyer's law (Eq. (3)). The indentation data for the material examined in the present study was plotted in Fig. 6. The data showed linear relationship, implying that the traditional Meyer law was suitable for describing the indentation data. The best-fit values of the parameters $A$ and $n$ were $3.36 \times 10^{-3}$, 1.718 , respectively, in terms of linear regression analyses. The calculated $n$ values pointing out the increase of indentation hardness with the decreasing applied indentation test load are in agreement with an ISE (Fig. 5) and with other reported results $[6,9]$. Although Upit and Varchenya [26] have suggested that $n$ value is indicative of the interaction of dislocation loops with one another and also with the crystal surface, the physical meanings of parameters $A$ and $n$ are not still satisfactory.

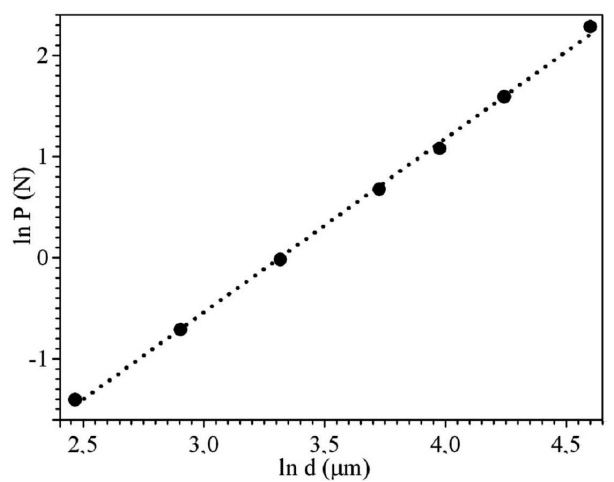

Fig. 6. Plot of $\ln \mathrm{P}$ vs. $\ln d$ according to the Meyer law.

On the basis of the elastic-plastic deformation hypothesis, Eq. (5) allows to estimate $d_{0}$ and $C_{2}$ parameters from the plot of $P^{1 / 2}$ versus $d$. Figure 7 shows such a plot of the test material. The obtained best-fit values of $C_{2}$ and $d_{0}$ parameters are $2.98 \times 10^{-2}$ and $5.06 \mu \mathrm{m}$, re- 
spectively. One can clearly perceive from the figure that all data points show apparent linearity with a very high correlation coefficient, $r^{2}=0.999$. At the first glance, this good linearity implies validity of the elastic plastic deformation approach to explain the origin of ISE. However, the estimated correction term $\left(d_{0}=5.06 \mu \mathrm{m}\right)$ value seems to be too large to be accepted especially at low loads. Thus, the ISE behavior depicted in Fig. 5 cannot be explained using the elastic recovery model. At least, the error in indentation size due to indenter tip blunting effect and the elastic recovery after indentation are not the only source of the ISE observed in the present study.

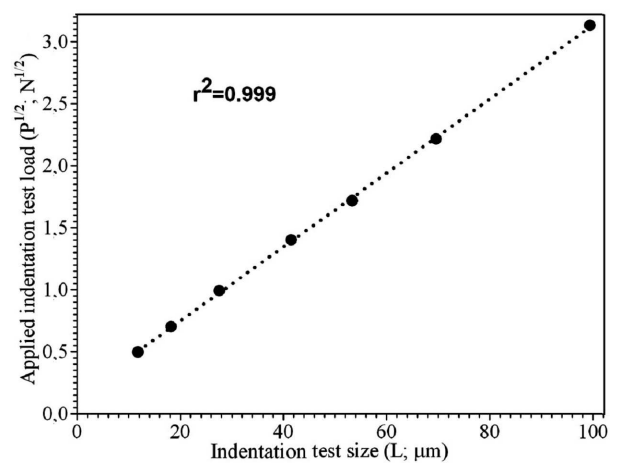

Fig. 7. Plot of $P^{1 / 2}$ vs. $L$ according to elastic/plastic deformation model.

PSR model may be considered to be a modified form of the Hays-Kendall approach to the ISE. The model treats the specimen's resistance to permanent deformation as a function of indentation size, rather than constant (i.e., $\left.W=a_{1} d\right)$ [27]. Li and Bradt concluded that this model might provide a satisfactory explanation for the origin of ISE in microhardness tests for different kinds of materials. Their formulation procedure is given by Eqs. (6) and (7).

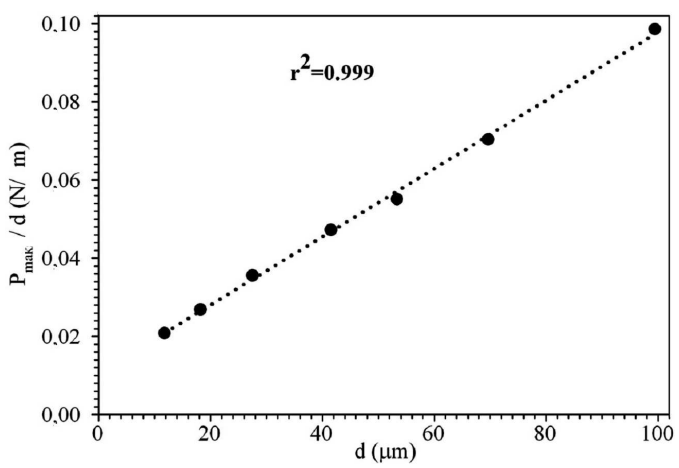

Fig. 8. Plots of $P_{\max } / d$ vs. $d$ according to the PSR model.

According to Eq. (7), a plot of $P / d$ versus $d$ should yield a straight line, theoretically. Figure 8 shows such a plot where $a_{1}$ and $a_{2}$ parameters can easily be calculated from the intersection point and slope of the curve, respec- tively. The best fit for $a_{1}$ and $a_{2}$ parameters and the corresponding load-independent hardness values $\left(H_{\mathrm{PSR}}\right)$ are $1.055 \times 10^{-2} \mathrm{~N} / \mu \mathrm{m}, 8.729 \times 10^{-4} \mathrm{~N} / \mu \mathrm{m}^{2}$ and $1.242 \mathrm{GPa}$, respectively.

On the other hand, Quinn and Quinn [28] have recently examined variation of microhardness with indentation load for a variety of ceramic materials. They observed that such hardness-load curve exhibited distinct transition to a plateau of constant hardness and claimed that such curve corresponded to the intrinsic hardness value of the materials. In the present study, Fig. 5 shows the transition point (about $2.94 \mathrm{~N}$ ) and the corresponding intrinsic hardness value is about $14.7 \mathrm{GPa}$. In the light of Quinn and Quinn [28] approximation, the load-independent-hardness value calculated by PSR model is far from the intrinsic hardness value for the $\beta$-SiAlON sample. Therefore, it may be concluded that PSR model may also be insufficient to explain the ISE behavior of the present SiAlON sample.

Hays-Kendall proposed that there exists a minimum applied test load $W$ (test specimen resistance) necessary to initiate plastic deformation and below which only elastic deformation occurs. According to their hypothesis Eq. (6) is modified to

$$
P_{\text {effective }}=P-W=C_{1} d^{2},
$$

where $C_{1}$ is a constant independent of the test load and $P-W$ is an effective indentation load. Replacing $P$ in Eq. (2) by $P-W$, one gets an equation to calculate the load-independent hardness as follows:

$$
H_{\mathrm{K}}=14.229 \frac{P-W}{L^{2}} .
$$

In Eq. (12) $L$ is equal to $d$. From Eq. (11) a plot of $P$ versus $L^{2}$ would yield a straight line. Such plot for the examined material in the present study is shown in Fig. 9. The correlation coefficient, $r^{2}$, is implying that Eq. (11) provides a satisfactory description of the indentation data for the examined test materials.

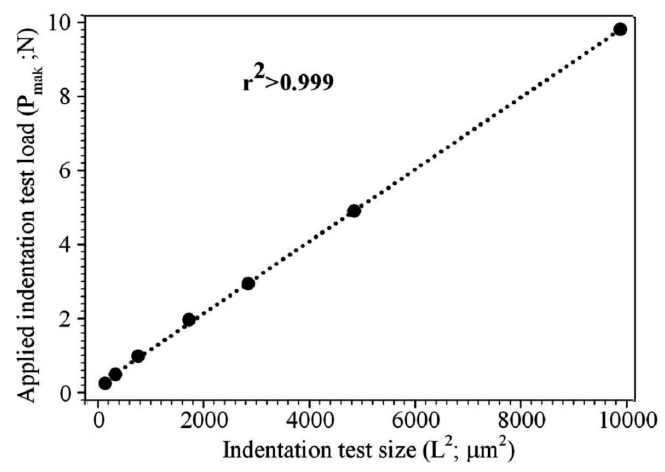

Fig. 9. Plots of applied indentation test load versus indentation test size according to the Hays-Kendall model.

The best-fit $W$ and $C_{1}$ parameters and the corresponding load-independent hardness values $\left(H_{\mathrm{HK}}\right)$ are $-0.191 \mathrm{~N}, 9.730 \times 10^{-4} \mathrm{~N} / \mu \mathrm{m}^{2}$, and $13.844 \mathrm{GPa}$, re- 
spectively. The $H_{\mathrm{HK}}$ value is closer to the plateau value compared with the results of the other models. Therefore, the Hays-Kendall model, which calculates the value of $H_{\mathrm{LI}}$, seems to be more reasonable than the others [29].

The small difference between the Knoop (plateau value about $14.4 \mathrm{GPa}$ in this study) and the Vickers hardness (plateau value about $16.3 \mathrm{GPa}$ in this study) numbers has been subject to some interesting discussion in the literature. For example, Shaw et al. [30], Atkinson et al. $[31,32]$, and Shi and Atkinson [33] have tried to explain the difference of the two hardness numbers, Knoop and Vickers, through the friction phenomenon which takes place between the material and the indenter, stating that friction was dependent of the indenter geometry. In addition, it has been reported by Lawn and Howes [34] and Marshall et al. [35] that an elastic recovery may occur after the indentation load, which is removed as the result of the mismatch between the plastic zone beneath the indentation and the surrounding elastic deformed material. Due to the specific shape of the indenter, the elastic recovery during the Vickers indentation is rather different than corresponding to the Knoop indentation [36].

On the other hand, Marshall et al. [37] have observed that the length of the minor diagonal of the Knoop indent is often shorter than those expected by taking into account the geometrical considerations of the indenter. This phenomenon is also attributed to the elastic recovery. Therefore, Marshall et al. [37], Blau [38], and Lima et al. [39] have proposed to express the ratio between width, $w$, and length, $L$, of the Knoop impression as a function of the ratio between the hardness, KHN, and the Young modulus, $E$, of the material by the following relationship:

$$
\frac{w}{L}=\frac{w^{\prime}}{L^{\prime}}-0.45 \frac{\mathrm{KHN}}{E},
$$

where $w^{\prime} / L^{\prime}$ theoretical ratio is equal to 0.1406 , calculated from the geometrical characteristics of the Knoop indenter. According to Eq. (13) the elastic modulus of the $\beta$-SiAlON sample is $161.450 \mathrm{GPa}$.

It is known $[40,41]$ that the concentration of $\mathrm{Al}$ and $\mathrm{O}$ in $\beta$-SiAlON is responsible for the variations in their physicochemical properties. For example [40], as the concentration rises, the properties of $\beta$-SiAlON change in the following way: lattice parameters ( $a$ from 7.6 to 7.72 , $c$ from 2.91 to $3.02 \AA$ ), Young's modulus (from $\approx 300$ to $\approx 200 \mathrm{GN} / \mathrm{m}^{2}$ ), density (from 3.2 to $3.1 \mathrm{~g} / \mathrm{cm}^{3}$ ), thermal conductivity, thermal expansion coefficient (from $3.4 \times 10^{-6}$ to $\approx 2.4 \times 10^{-6}$ ) hardness from (1700 to $1300 \mathrm{~kg} / \mathrm{mm}^{2}$ ) [41].

The Young modulus value is also changing with property of material. For example, the decrease in density (or increase in porosity) has a strong effect on Young's modulus in that any small increase in porosity (equivalent to decrease in density) leads to a large decrease in Young's modulus [42]. In addition, Sahin et al. [43] calculated elastic modulus value $88.3 \mathrm{GPa}$ of porous SiAlON ceramic using depth sensing indentation tecnique.

\section{Conclusion}

Indentation microhardness of the $\beta$-SiAlON ceramic was measured using the Knoop and Vickers indenters. The results can be summarized as follows:

1. The measured Vickers and Knoop microindentation hardness values of the sample are obviously load-dependent.

2. The variation of $H_{\mathrm{V}}$ follows the reverse ISE trend, i.e., an increase in $H_{\mathrm{V}}$ with respect to load in the low-load region beyond where it becomes relatively constant.

3. The variation of $H_{\mathrm{K}}$ follows the normal ISE trend, i.e., a decrease in $H_{\mathrm{V}}$ with respect to load in the low-load region beyond where it becomes relatively constant. This type of variation in $H_{\mathrm{K}}$ can be explained by Meyer's relationship up to a certain value of load. However, no useful knowledge of the origin of the observed ISE is gained from this empirical equation.

4. Calculated value of $H_{\mathrm{PSR}}$ (based on the proportional specimen resistance model, PSR) is obviously below the plateau region; the PSR model does not accurately describe the ISE behaviour observed in the $\beta$-SiAlON sample.

5 . The ISE behaviour of the $\beta$-SiAlON sample can be explained successfully by using the concept of Hays-Kendall model. The measured load-independent hardness value is more consistent with that calculated by the PSR model.

6. The Young modulus, $E$, of the material is 161.450 GPa.

\section{Acknowledgments}

The financial support from research foundation of Mustafa Kemal University (grant no. 08 F 0501) is also gratefully acknowledged. The partial financial support by 6th FP under the project no. ACTIVATION NMP2-CT-2004-505885 is also gratefully acknowledged.

\section{References}

[1] J.B. Quinn, G.D. Quinn, J. Mater. Sci. 32, 4331 (1997).

[2] G. Constantinidis, R.D. Tomlinson, Philos. Mag. Lett. 57, 91 (1988).

[3] C. Ascheron, C. Haase, G. Kuhn, H. Neumann, Cryst. Res. Technol. 24, K33 (1989).

[4] R.K. Marwaha, B.S. Shah, Cryst. Res. Technol. 23, K63 (1988).

[5] R. Bajpai, S.C. Datt, Indian J. Pure Appl. Phys. 24, 254 (1986). 
[6] K. Sangwal, Mater. Chem. Phys. 63, 145 (2000).

[7] J. Gong, H. Miao, Z. Zhao, Z. Guan, Mater. Sci. Eng. A 303, 179 (2001).

[8] B. Basu, Mukhopadhyay, N.K. Manisha, , J. Eur. Ceram. Soc. 29, 801 (2009).

[9] O. Şahin, O. Uzun, U. Kölemen, N. ve Uçar, J. Phys., Condens. Matter 19, 306001 (2007).

[10] K. Sangwall, B. Surowska, P. Blaziak, Mater. Chem. Phys. 77, 511 (2002).

[11] D.D. Graaf, M. Braciszewicz, H.T. Hintzen, M. Sopicka-Lizer, G. De With, J. Mater. Sci. 39, 2145 (2004).

[12] F.I. Bulić, I. Zalite, N. Zhilinska, J. Eur. Ceram. Soc. 24, 3303 (2004).

[13] X. Xu, T. Nishimura, T. Hirosaki, R.-J. Xie, Y. Yamamoto, H. Tanaka, Nanotechnology 16, 1569 (2005).

[14] M. Sopicka-Lizer, T. Pawlik, T. Włodek, M. Tańcula, G. Chernik, Key Eng. Mater. 352, 179 (2007).

[15] P.O. Käll, Chem. Scr. 28, 439 (1988).

[16] T. Ekström, P.O. Käll, M. Nygren, P.O. Olsson, J. Mater. Sci. 24, 1853 (1989).

[17] B. Basu, Mukhopadhyay, N.K. Manisha, , J. Eur. Ceram. Soc. 29, 801 (2009).

[18] S. Sebastian, M.A. Khadar, J. Mater. Sci. 40, 1655 (2005).

[19] K. Sangwal, B. Surowska, Mater. Res. Innovat. 7, 91 (2003).

[20] P. Feltham, R. Banerjee, J. Mater. Sci. 27, 1626 (1992).

[21] G.R. Antis, P. Chantikol, B.R. Lawn, D.B. Marshall, J. Am. Ceram. Soc. 64, 533 (1981).

[22] G.M. Pharr, D.S. Harding, W.C. Oliver, in: Mechanical Properties and Deformation Behavior of Materials Having Ultra-Fine Microstructures, Eds. M. Nastasi, D. M Parkin, H. Gleiter, Kluwer Academic Press, 1993, p. 449.

[23] C. Hays, E.G. Kendall, Metallurgy 6, 275 (1973).

[24] H. Li, R.C. Bradt, J. Mater. Sci. 28, 917 (1993).
[25] H. Li, R.C. Bradt, J. Mater. Sci. 31, 1065 (1996).

[26] G.P. Upit, S.A. Varchenya, in: The Science of Hardness Testing and Its Research Applications, Eds. J.H. Westbrook, H. Conrad, American Society for Metals, Metals Park, OH 1973, p. 144.

[27] H. Li, R.C. Bradt, J. Mater. Sci. 28, 917 (1993).

[28] J.B. Quinn, G.D. Quinn, J. Mater. Sci. 32, 4331 (1997).

[29] E. Sahin, M.Sc. Thesis, Mustafa Kemal University, 2011.

[30] C. Shaw, Y. Li, H. Jones, Mater. Lett. 28, 33 (1996).

[31] M. Atkinson, H. Shi, Mater. Sci. Technol. 5, 613 (1989).

[32] M. Atkinson, J. Mater. Res. 10, 2908 (1995).

[33] H. Shi, M. Atkinson, J. Mater. Sci. 25, 2111 (1990).

[34] B.R. Lawn, V.R. Howes, J. Mater. Sci. 16, 2745 (1981).

[35] D.B. Marshall, T. Noma, A.G. Evans, J. Am. Ceram. Soc. 65, 175 (1982)

[36] D. Chicot, D. Mercier, F. Roudet, K. Silva, M.H. Staia, J. Lesage, J. Eur. Ceram. Soc. 27, 1905 (2007).

[37] D.B. Marshall, T. Noma, A.G. Evans, J. Am. Ceram. Soc. 65, 175 (1982).

[38] P.J. Blau, The Lab Handbook of Microindentation Hardness Testing., Blue Rock Technical Publications, Oak Ridge, TN 2000, Sect. 5.2.

[39] R.S. Lima, A. Kucuk, C.C. Berndt, Surf. Coat. Technol. 135, 166 (2001).

[40] L.J. Gauckler, S. Prietzel, G. Bodmer, G. Petzow, in: Nitrogen Ceramics, Ed. F.L. Riley, Riby, Leiden, Noordhoff 1997, p. 529.

[41] G.Z. Cao, R. Metselaar, Chem. Mater. 3, 242 (1991).

[42] Z. Krstic, V.D. Krstic, J. Europ. Ceram. Soc. 28, 1723 (2008).

[43] O. Şahin, O. Uzun, M. Sopicka-Lizer, H. Göçmez, U. Kölemen, J. Europ. Ceram. Soc. 28, 1235 (2008). 